\title{
Role of CYP1A2 polymorphisms in breast cancer risk in women
}

\author{
IMENE AYARI $^{1}$, UGO FEDELI $^{2}$, SAAD SAGUEM $^{1}$, SAMIR HIDAR $^{3}$, SAIDA KHLIFI $^{1}$ and SOFIA PAVANELLO ${ }^{4}$ \\ ${ }^{1}$ Metabolic Biophysics and Applied Pharmacology Laboratory, Department of Biophysics, University of Sousse, Sousse 4002, \\ Tunisia; ${ }^{2}$ Epidemiologic System Veneto Region (SER), I-35131 Padova, Italy; ${ }^{3}$ Department of Gynecology-Obstetrics, \\ Hospital Farhat Hached, University of Sousse, Sousse 4002, Tunisia; ${ }^{4}$ Occupational Health Section, \\ Department of Cardiological, Thoracic and Vascular Sciences, University of Padova, I-35128 Padova, Italy
}

Received July 13, 2012; Accepted October 2, 2012

DOI: $10.3892 / \mathrm{mmr} .2012 .1164$

\begin{abstract}
Cytochrome P4501A2 (CYP1A2) is a key enzyme in the etiology of breast cancer (BC). It is involved in breast carcinogen activation [aromatic (AAs) and heterocyclic amines (HAs), polycyclic aromatic hydrocarbons (PAHs)], in the production of beneficial oestrogen [2-hydroxyestrone (2-OHE1)] and in converting arachidonic acid (AAc) to epoxyeicosatrienoic acids (EETs), which have anti-inflammatory properties. Within a hospital-based case-control study, the effect of functional CYP1A2 variants [-3860G/A (rs2069514), -2467T/delT (rs3569413), -163C/A (rs762551)] and their interactions with environmental factors in $\mathrm{BC}$ risk was investigated. The study population included $125 \mathrm{BC}$ cases and 43 non-cancer controls. Genotyping was performed in RT-PCR using Taqman assays. The gene-environment interaction was appraised using a case-only study design. We found that the $-3860 A$ variant, independently from environmental factors, as well as by interacting with fried foods $(\mathrm{p}=0.025)$ and indoor exposure to pollutants $(\mathrm{p}=0.050)$, reduced the risk of $B C(p=0.025)$, whereas its interaction with coffee $(p=0.045)$ increased the $\mathrm{BC}$ risk. This is the first study indicating that the $-3860 A$ variant, by decreasing CYP1A2 activity, modifies $\mathrm{BC}$ risk by interacting with environmental factors, thereby supporting the hypothesis that reduced CYP1A2 activity contributes to $\mathrm{BC}$ risk in different ways, for example, it may be
\end{abstract}

Correspondence to: Dr Sofia Pavanello, Occupational Health Section, Department of Cardiological, Thoracic and Vascular Sciences, University of Padova, Via Giustiniani 2, I-35128 Padova, Italy

E-mail: sofia.pavanenello@unipd.it

Abbreviations: AAc, arachidonic acid; AA, aromatic amines; CYP1A2, cytochrome P4501A2; EETs, epoxyeicosatrienoic acids; $\mathrm{HA}$, heterocyclic aromatic amine; $\mathrm{PAH}$, polycyclic aromatic hydrocarbon

Key words: breast cancer, CYP1A2 polymorphism, gene-environment interaction, CYP1A2 inducibility, oestrogen hydroxylation, coffee intake, fried food, indoor exposure, breast inflammation protective by reducing the activation of pro-carcinogens such as AAs, HAs and PAHs, but would increase risk by reducing the beneficial formation of 2-OHE1 and EETs.

\section{Introduction}

As in all ethnic groups, breast cancer (BC) is the most common cancer in women from Tunisia, although inflammatory BC is a Tunisian peculiarity (1). An increased BC incidence (age-standardized rate per 100,000 women) was observed: 16.7 in 1994 (2) to 29.2 in 2007 (3), which however, remains lower than that of developed countries (approximately 80) (2,3).

Human cytochrome P4501A2 (CYP1A2) is one of the major CYPs in the human liver and is a key enzyme, not only in the activation of the main suspected breast carcinogens, such as aromatic (AAs) and heterocyclic amines (HAs) and polycyclic aromatic hydrocarbons (PAHs), present in cigarette smoke and in fried and grilled meat $(4,5)$, but also in hydroxylation of oestrogens $(6,7)$ and in the metabolism of arachidonic acid (AAc) (8). AAc is involved in inflammation and breast carcinogenesis (9). Therefore, modulation of CYP1A2 activity may be important in the aetiology of BC.

Environmental and genetic factors influence the activity of CYP1A2. Tobacco smoking and consumption of fried and grilled food, coffee and cruciferous vegetables (i.e., broccoli-family) (10-15) increases CYP1A2 activity in humans. However, intake of apiaceous-like vegetables and the use of oral contraceptives decrease this activity (13). CYP1A2 activity is also modulated by specific polymorphisms in the CYP1A2 gene (16-21). The CYP1A2 polymorphisms located in the 5'-non-coding promoter region [-3860G/A (rs2069514), -2467T/delT (rs3569413)] and in intron 1 [-163C/A (rs762551)] of the CYP1A2 gene modified CYP1A2 activity of smokers, measured by the urinary caffeine metabolic ratio (CMR) (16-21). The -2467delT polymorphism was also found by our group to be a significant risk modifier of smoking-induced lung and bladder cancer $(22,23)$. A number of studies have reported the association between the $-164 A / C$ polymorphism and $\mathrm{BC}$ risk (24), however the results were inconclusive. To the best of our knowledge, no molecular epidemiological study has been published on the involvement of the other functional CYP1A2 polymorphisms, such as -3860 G/A and $-2467 T /$ delT, on the risk of $\mathrm{BC}$. 
In this study, we examined the role of functional $C Y P 1 A 2$ polymorphisms $(-3860 \mathrm{G} / \mathrm{A}, 2467 \mathrm{~T} / \mathrm{delT},-163 \mathrm{C} / \mathrm{A})$ in modulating the relationship between exposure to environmental factors and risk for BC in Tunisian women. The aim was to identify new genetic characteristics that contribute to individual susceptibility to $\mathrm{BC}$. The interaction was appraised by using a case-only study design $(25,26)$.

\section{Materials and methods}

Subjects. Study subjects included 125 women with histologically confirmed BC. All cases of BC were recruited from October 2007 until the end of 2008 at the Centre Hospitalier Universitaire 'Farhat Hached'. The control group collected in the same period comprised 43 ethnically and gender-matched healthy subjects. Controls were recruited from the occupational medicine service during their annual check-up. Trained interviewers informed all participants of the study objectives and collected personal data including coffee and tea consumption, alcohol drinking, job type, possible elevated non-occupational genotoxic-exposures, including smoking, diet, indoor and outdoor exposure, and consumption of vegetables by means of a structured questionnaire, as previously described $(22,23)$. All of the information regarding participants was rendered anonymous following collection of data and blood samples. At recruitment, written informed consent was obtained from each study participant prior to interview and blood collection for genetic analyses. The Ethics Committee of the Hospital of Sousse approved the research study and the study has therefore been performed in accordance with the ethical standards of the 1964 Declaration of Helsinki. Individuals with dietary intake of genotoxins were those who reported consumption of grilled (PAHs) and fried meat (HAs); individuals with indoor exposure to pollutants were those who reported at least 1 of several exposure sources, including use of fireplace, coal or wood-stove as heating at home; or passive exposure to tobacco smoke, as previously described $(22,23)$. Individuals with high vegetable consumption were those who reported a daily intake of tomatoes, onions and peppers, typical vegetables in a Mediterranean diet.

Blood and DNA collection. A sample $(5 \mathrm{ml})$ of whole blood was collected from each subject in a K3ETDA vacutainer tube (violet cap). DNA was extracted from cells using protocols for genomic DNA isolation with the Promega Wizard genomic DNA purification kit (Promega, Italy). The extracted DNA was dissolved in $300 \mu \mathrm{l}$ of TE buffer, divided in two aliquots and stored at $-20^{\circ} \mathrm{C}$ until shipping to the Department of Cardiological, Thoracic and Vascular Sciences, University of Padova (Italy), where quality and quantity control and genotype analyses were performed. DNA was free of RNA or protein contamination, as confirmed by the 260/230 and 260/280 nm absorbance ratios of DNA, which were always approximately 2.3 and 1.7 , respectively, as previously described (20).

Genotyping. Genotyping was performed using commercially available Taqman drug metabolism genotyping assays: C__15859191_30 'rs2069514', C__60142977_10 'rs35694136', C___8881221_40 'rs762551' (Applied Biosystems, Foster City, CA, USA), as previously described (27). Briefly, reactions were set up according to the manufacturer's instructions and the samples were run on a Steponeplus Real-Time instrument (Applied Biosystems, Monza, Italy). Allelic discrimination was performed using the SDS software v2.3 (Applied Biosystems). The $25 \mu \mathrm{l}$ reactions in 96-well plates included $12.5 \mu \mathrm{l}$ TaqMan Universal PCR Master Mix, No AmpErase UNG (2X), $1.25 \mu 1$ Drug Metabolism Genotyping Assay Mix (20X) and DNA $11.25 \mu \mathrm{l}(1 \mathrm{ng} / \mu \mathrm{l})$. Quality-control measures included validation of the results by polymerase chain reaction-restriction fragment length polymorphism (PCR-RFLP) genotyping and the blind repeat of $10 \%$ of samples for CYP1A2 polymorphic sites (-3860 G/A, -2467T/delT and $-163 C / A)$, as previously described (19). Briefly for the RFLP analysis, all PCR reactions $(25 \mu \mathrm{l})$ were performed on a GeneAmp PCR System 9700 (Applied Biosystems, Monza, Italy), with each mastermix (Life Technologies, Monza, Italy) comprising 0.2 mM dNTPs, 1 unit of Taq polymerase, the appropriate concentration of $\mathrm{MgCl}_{2}$ (1.75 and $1.25 \mathrm{mM}$ ) and $0.4 \mu \mathrm{M}$ of each primer (Life Technologies). Variants $-3860 \mathrm{G} / \mathrm{A},-2467 \mathrm{~T} / \mathrm{delT}$ and -163C/A were identified using DdeI, NdeI and ApaI restriction enzymes purchased from New England Biolabs (Milan, Italy) (20).

Statistical analysis. Statistical comparisons were made between the cases and controls using Fisher's exact test. To investigate whether the genotype was in Hardy-Weinberg equilibrium, distribution of the observed and expected genotype frequencies were compared using a $\chi^{2}$ test. Pearson's $\chi^{2}$ test was used to test the association between cases and controls and genotype frequencies. The interaction of genotypes with the effects of environmental and dietary exposures on BC risk was evaluated by a case-only study approach and Pearson's $\chi^{2}$ test was used to test the association. Individuals with high vegetable consumption were those who reported a daily intake ( $\geq 20$ servings/week) of tomatoes, onions and peppers, typical vegetables in a Mediterranean diet.

\section{Results}

Case-control study. The characteristics of BC patients $(n=125)$ and controls $(n=43)$ are shown in Table I. All the subjects were non-smoking, non-alcohol-drinking and declared not to be exposed to passive smoke, therefore, these variables were not further considered. The variables considered were not homogeneously distributed in the study population (i.e., indoor and outdoor exposure to pollutants, intake of vegetables, fruits, daily coffee and tea, education). In particular, cancer cases were significantly older than the controls $(\mathrm{P}<0.0001)$, and consequently the majority of cases were postmenopausal $(\mathrm{P}<0.0001)$. Both cases and controls reported a high consumption of tomatoes, onions and peppers (from 5 to 7 or more servings of vegetables/week), while apiaceous (i.e., carrots) and cruciferous (i.e., cabbages) vegetables and fruits were consumed much less frequently. With the exception of one case, the women did not use oral contraceptives, therefore a potential factor influencing CYP1A2 activity (11) was absent.

Table II shows the observed and expected genotypes for CYP1A2 -3860 G/A (determined in 109 cases and 41 controls), $-2467 T /$ delT (determined in 117 cases and 42 controls) and $-163 \mathrm{C} / \mathrm{A}$ (determined in 108 cases and 38 controls). The expected genotype frequencies were not significantly different from the 
Table I. Characteristics of the sample population.

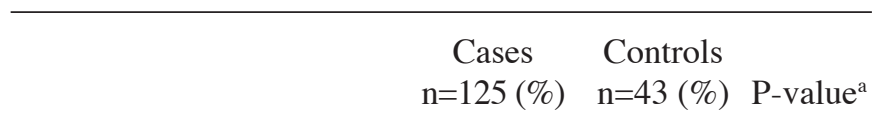

\section{Gender}

Male

Female

$0(0) \quad 0(0)$

$125(100)$

Smoking status

Current

Never

$\begin{array}{cc}0 & 0 \\ 125(100) & 43(100)\end{array}$

Alcohol drink

Current

Never

Age (years)

$$
\begin{aligned}
& <40 \\
& 40-44 \\
& 45-49 \\
& 50-54 \\
& 55-59 \\
& 60-64 \\
& 65+
\end{aligned}
$$

BMI

$$
\begin{aligned}
& \text { Normal range } \\
& \left(18.5-24.99 \mathrm{~kg} / \mathrm{m}^{2}\right) \\
& \text { Underweight } \\
& \left(<18.50 \mathrm{~kg} / \mathrm{m}^{2}\right) \\
& \text { Overweight } \\
& \left(25-29.99 \mathrm{~kg} / \mathrm{m}^{2}\right)
\end{aligned}
$$

Obese

$\left(>29.99 \mathrm{~kg} / \mathrm{m}^{2}\right)$

Menopausal status

Yes

No

Fried food consumption

Never

$<1$ serving/week

1-3 servings/week

$>3$ servings/week

Grilled food consumption

Never

$<1$ servings/week

1-3 servings/week

$>3$ servings/week

Indoor exposure

Passive smoke exposure

Use of coal or wood-stove

as heating at home

Outdoor exposure

Urban, light traffic

Urban, normal traffic

Urban, heavy traffic

Rural

1

Apiaceous (carrots) consumption $<1$ serving/month 1 serving/week
$43(100)$

$$
0
$$$$
125
$$

$\begin{array}{ll}22 & 2 \\ 16 & 10 \\ 15 & 1 \\ 19 & 2 \\ 17 & 2 \\ 15 & 0 \\ 21 & 0\end{array}$

46

2

47

31

08

13

0

52

73

1

1

ND

ND

$$
\text { ND }
$$

0

43

$<0.0001$

10

1

2

2

0

0

$$
21
$$

$<0.0001$

0

17

5

$<0.0001$

0

43

$<0.0001$

0

6

23

14

$<0.0001$

0

\begin{tabular}{|c|c|c|c|}
\hline & $\begin{array}{c}\text { Cases } \\
\mathrm{n}=125(\%)\end{array}$ & $\begin{array}{l}\text { Controls } \\
\mathrm{n}=43(\%)\end{array}$ & P-value \\
\hline Cruciferous consumption & & & $<0.0001$ \\
\hline$<1$ serving/month & 80 & 0 & \\
\hline 1 serving/week & 43 & 43 & \\
\hline Tomato & & & $<0.0001$ \\
\hline$<7$ servings/week & 82 & 0 & \\
\hline$>7$ servings/week & 43 & 43 & \\
\hline Onion & & & $<0.0001$ \\
\hline$<7$ servings/week & 55 & 0 & \\
\hline$>7$ servings/week & 70 & 43 & \\
\hline Pepper & & & $<0.0001$ \\
\hline$<5$ servings/week & 82 & 0 & \\
\hline$>5$ servings/week & 43 & 43 & \\
\hline $\begin{array}{l}\text { Daily coffee consumption } \\
\text { (cups) }\end{array}$ & & & $<0.0001$ \\
\hline None & 31 & 0 & \\
\hline 1 & 93 & 13 & \\
\hline$\geq 2$ & 2 & 30 & \\
\hline $\begin{array}{l}\text { Daily tea consumption } \\
\text { (cups) }\end{array}$ & & & $<0.0001$ \\
\hline None & 9 & 6 & \\
\hline 1 & 83 & 26 & \\
\hline $2-4$ & 7 & 11 & \\
\hline$\geq 5$ & 27 & 0 & \\
\hline Education level (years) & & & $<0.0001$ \\
\hline 0, none & 64 & 0 & \\
\hline $1-6$, elementary school & 29 & 4 & \\
\hline $7-14$, secondary school & 28 & 20 & \\
\hline$>14$, university & 5 & 19 & \\
\hline
\end{tabular}

43

0

0

ND

43

0

1

12

30

0

$<0.0001$
Table I. Continued.

${ }^{a}$ Fisher's exact test. BMI, body mass index.

observed frequencies in BC cases and controls when separately considered, indicating that they were in Hardy-Weinberg equilibrium. The frequencies of $-3860 \mathrm{~A}(10 \%),-2467 \mathrm{del} T(18 \%)$ and $-163 A(61 \%)$ are similar to those found in our previous study on healthy Caucasian volunteers, in which the frequencies were 4, 24 and 67\%, respectively (20). The incidence of CYPIA2 $-3860 A$ (Table III) was significantly lower among BC cases, indicating a decreased risk of $\mathrm{BC}$ associated with this $C Y P 1 A 2$ genotype (odds ratio; $95 \%$ confidence interval: 0.35 ; $0.14-0.88$, $\mathrm{P}=0.025)$. By contrast, distributions of the CYPIA2 -2467T/ delT or -2467 delT/delT and $-163 A / C$ or $A / A$ genotypes among $\mathrm{BC}$ cases and controls were similar, indicating no overall effect of these polymorphisms on $\mathrm{BC}$ risk. However, the case-control comparison appears to be limited by the large differences in baseline characteristics, in particular differences of age.

Case-only study. We performed a case-only study analysis to appraise the interaction between genotypes and environmental exposure to risk factors (Table IV). All the significant associations involve the $-3860 A / G$ (rs2069514) polymorphism: the 
Table II. CYP1A2 genotype frequencies in BC cases and controls.

\begin{tabular}{|c|c|c|c|c|c|c|}
\hline \multirow[b]{2}{*}{ CYP1A2 genotype } & \multicolumn{3}{|c|}{$\mathrm{BC}$ cases } & \multicolumn{3}{|c|}{ Controls } \\
\hline & $\mathrm{N}$ & Observed frequency & Expected frequency ${ }^{a}$ & $\mathrm{~N}$ & Observed frequency & Expected frequency ${ }^{a}$ \\
\hline$-3860 G / G$ & 98 & 90 & 90 & 31 & 76 & 76 \\
\hline$G / A$ & 11 & 10 & 10 & 9 & 22 & 22 \\
\hline$A / A$ & 0 & & & 1 & 2 & 2 \\
\hline$-163 C / C$ & 17 & 14 & 15 & 4 & 9 & 11 \\
\hline$C / A$ & 58 & 50 & 48 & 20 & 48 & 44 \\
\hline$A / A$ & 42 & 36 & 37 & 18 & 43 & 45 \\
\hline$-2467 T / T$ & 74 & 68 & 66 & 25 & 66 & 67 \\
\hline T/del $T$ & 29 & 27 & 30 & 13 & 34 & 30 \\
\hline delT/delT & 5 & 5 & 4 & & & 3 \\
\hline
\end{tabular}

${ }^{\mathrm{a} A c c o r d i n g}$ to Hardy-Weinberg. CYP1A2, cytochrome P4501A2; BC, breast cancer.

Table III. Risk of BC associated with the CYP1A2 genotypes.

\begin{tabular}{lcccc}
\hline CYP1A2 genotype & Cases & Controls & Pearson $\chi^{2}$ & P-value \\
\hline$-3860 \mathrm{G} / G$ & 98 & 31 & & \\
G/ A & 11 & 10 & 5.0591 & 0.025 \\
$-163 \mathrm{C} / \mathrm{C}$ & 17 & 4 & & \\
C/A A/A & 38 & 100 & 1.0072 & 0.604 \\
-2467 T/T & 74 & 25 & & \\
T/delT delT/delT & 34 & 13 & 0.0959 & 0.757 \\
\hline
\end{tabular}

CYP1A2, cytochrome P4501A2; BC, breast cancer.

inducible A variant interacted mainly with coffee $(\mathrm{P}=0.045)$ to increase the number of $\mathrm{BC}$ cases (there were more $\mathrm{BC}$ cases with a high consumption of coffee). However, we observed a significant interaction of the A variant with fried food intake $(\mathrm{P}=0.026)$ and indoor exposure $(\mathrm{P}=0.050)$ and a borderline interaction with grilled food $(\mathrm{P}=0.075)$ to decrease the number of $\mathrm{BC}$ cases. Subjects with the A variant present the variants $-163 A$ and $-2467 d e l T$. No interaction was found with BMI, vegetable and tea consumption, nor with other $-2467 T /$ delT and $-163 C / A$ variants (Table IV).

\section{Discussion}

This study shows that the $-3860 A$ variant, by decreasing CYP1A2 activity $(16,19)$, modified BC risk by interacting with environmental exposures, in particular with dietary habits. The $-3860 A$ variant reduced the risk of $\mathrm{BC}$ both independently from environmental factors and by interacting with fried foods and indoor polyaromatic exposure, whereas its interaction with a high intake of coffee increased BC risk. To the best of our knowledge, this is the first study reporting such an interaction and is in agreement with the fact that this point mutation significantly decreases CYP1A2 activity $(16,19)$.
A number of studies have reported the association between the $C Y P 1 A 2-164 A / C$ polymorphism and $\mathrm{BC}$ risk (24,28-36), however, the results remain inconclusive even in the metaanalysis study (24). The variant $-163 C$ is located at intron 1 , in a position not directly involved in the $C Y P 1 A 2$ induction mechanism (37). The $-3860 G / A$ is in the regulatory region of the gene (-2964 position in the gene flanking region), near the binding region [positions -2495 and -2000 (37)] of the xenobiotic responsive element (XRE), which is involved in the CYP1A2 induction mechanism. In agreement with Nakajima et al (19), we suggest that the $-3860 G / A$ polymorphism affects the binding of the activator to the XRE regulating the expression of CYP1A2. Specifically, in the nucleus the ligand AhR is activated and forms a heterodimer with the Ah receptor nuclear translocator (Arnt) (38), as a consequence of the binding with polyaromatic chemicals $(37,39)$. This heterodimer formation is required to activate the transcription of $C Y P 1 A 2$ through binding the XRE (37-39). Our results suggest that the $-3860 G / A$ polymorphism, by interacting with polyaromatic chemicals, such as those present in fried food (15), coffee (10) and indoor exposure (40), may modify this binding site (e.g., chromatin structure) (37), thereby decreasing CYP1A2 expression. Given the role of the CYP1A2 in the activation of procarcinogens present in fried food and indoor pollutants (HAs and PAHs) and the modulating (decreasing) effect of the $-3860 \mathrm{G} / \mathrm{A}$ polymorphism on CYP1A2 activity (16-19), our results suggest that the ensuing decreased carcinogen activation may be protective for BC development. However, the consequent lower CYP1A2 activity may lead to other conditions of risk for BC development. These conditions include a reduced formation of the beneficial 2-hydroxyestrone (2-OHE1) that mutually allows the formation of the carcinogenic $16 \alpha$-hydroxyestrone (16 $\alpha$-OHE1) (41). A high CYP1A2 level in fact has a protective effect on $\mathrm{BC}$ risk by increasing the 2-hydroxyestrone (OHE)/16 $\alpha$-OHE1 ratio $(42,43)$. By contrast, an increased formation of $16 \alpha-\mathrm{HE}$ has been associated with an elevated risk of BC (44), since $16 \alpha$-HE binds to DNA, creating adducts, which may subsequently induce gene mutations $(45,46)$. Additionally, CYP1A2 metabolizes AAc to epoxyeicosatrienoic acids (EETs), which 
Table IV. Interaction of CYP1A2 genotype and environmental exposure on the risk of BC.

\begin{tabular}{|c|c|c|c|c|c|c|}
\hline & $-3860 G / G$ & $G / A$ & $-2467 T / T$ & T/delT delT/delT & $-163 C / C$ & $C / A A / A$ \\
\hline \multicolumn{7}{|c|}{ Coffee (servings/week) } \\
\hline 0 & 27 & 0 & 24 & 6 & 3 & 26 \\
\hline$\geq 1$ & 71 & 11 & 50 & 28 & 14 & 74 \\
\hline Pearson $\chi^{2} / \mathrm{P}$-value & $4.03 / 0.045$ & & $2.54 / 0.111$ & & $0.54 / 0.320$ & \\
\hline \multicolumn{7}{|c|}{ Fried food (servings/week) } \\
\hline$<1$ & 37 & 8 & 30 & 15 & 8 & 41 \\
\hline$\geq 1$ & 61 & 3 & 43 & 19 & 9 & 58 \\
\hline Pearson $\chi^{2} / \mathrm{P}$-value & $4.99 / 0.0255$ & & $0.09 / 0.768$ & & $0.18 / 0.460$ & \\
\hline \multicolumn{7}{|c|}{ Indoor (servings/week) } \\
\hline 0 & 71 & 11 & 53 & 27 & 13 & 76 \\
\hline 2 & 26 & 0 & 21 & 7 & 4 & 24 \\
\hline Pearson $\chi^{2} / \mathrm{P}$-value & $3.88 / 0.050$ & & $0.74 / 0.391$ & & $0.002 / 0.671$ & \\
\hline \multicolumn{7}{|c|}{$\begin{array}{l}\text { Tomatoes+onions+peppers } \\
\text { (servings/week) }\end{array}$} \\
\hline$<20$ & 65 & 8 & 54 & 24 & 11 & 68 \\
\hline$\geq 20$ & 33 & 3 & 19 & 10 & 6 & 44 \\
\hline Pearson $\chi^{2} / \mathrm{P}$-value & $0.73 / 0.477$ & & $0.134 / 0.714$ & & $0.099 / 0.753$ & \\
\hline \multicolumn{7}{|l|}{$\operatorname{BMI}\left(\mathrm{kg} / \mathrm{m}^{2}\right)$} \\
\hline$\leq 29.99$ & 69 & 8 & 57 & 24 & 12 & 75 \\
\hline$>29.99$ & 29 & 2 & 17 & 10 & 5 & 25 \\
\hline Pearson $\chi^{2} /$ P-value & $0.41 / 0.52$ & & $0.52 / 0.473$ & & $0.15 / 0.700$ & \\
\hline \multicolumn{7}{|l|}{ Tea (servings/week) } \\
\hline$<6$ & 73 & 10 & 54 & 28 & 14 & 78 \\
\hline$\geq 6$ & 25 & 1 & 20 & 6 & 3 & 22 \\
\hline Pearson $\chi^{2} / \mathrm{P}$-value & $1.47 / 0.226$ & & $1.12 / 0.289$ & & $0.16 / 0.686$ & \\
\hline \multicolumn{7}{|c|}{ Grilled food (servings/week) } \\
\hline$<3$ & 63 & 10 & 52 & 20 & 11 & 64 \\
\hline$\geq 3$ & 35 & 1 & 21 & 14 & 6 & 36 \\
\hline Pearson $\chi^{2} / \mathrm{P}$-value & $3.17 / 0.075$ & & $1.62 / 0.203$ & & $0.003 / 0.956$ & \\
\hline
\end{tabular}

Bold, statistically significant comparisons. CYP1A2, cytochrome P4501A2; BC, breast cancer; BMI, body mass index.

have anti-inflammatory and anti-apoptotic functions $(8,9)$. Therefore, decreased CYP1A2 activity may contribute to a decrease in EET production and generate an inflammatory microenvironment, all suitable conditions for the development and progression of $\mathrm{BC}(8)$.

The strengths of this study include the case-only study design, the discovery of a new genetic polymorphism that modulates susceptibility to $\mathrm{BC}$ by interacting with personal behaviors, and the good characterization of the study population with the thorough and reliable collection of several personal, occupational and environmental variables. The case-only study design is a powerful method for studying gene-environment interactions, as it achieves greater statistical power than a case-control study of the same sample size $(24,25)$. We have previously used the same design in studies of lung and bladder cancer $(21,22)$. The weaknesses of the study include that only three variants were considered in relation to $\mathrm{BC}$ risk and due to the low sample size no haplotype analysis could be performed. Additionally, the case-control comparison appears to be limited by large differences in the baseline characteristics of our study population. However, the significant association with variant $-3860 A$ was also found in the case-only study. We observed that all the subjects with the $-3860 A$ variant present the variants $-163 A$ and $-2467 d e l T$. Moreover, the studied $C Y P 1 A 2$ variants are common in the human population and $\mathrm{BC}$ is a frequent cancer in women. Similarly, consumption of coffee and meals with fried food, as well as indoor exposure to polyaromatic compounds are prevalent not only among Tunisian women, and CYP1A2 is involved in their metabolism. Therefore, these variants may have an impact in public health.

In conclusion, this is the first study indicating that the $-3860 A$ variant modifies $\mathrm{BC}$ risk by interacting with environmental exposures. The decreasing CYP1A2 activity, deriving from the interaction of the $-3860 \mathrm{~A}$ variant with coffee, fried foods and indoor exposure to pollutants, supports the hypothesis that a reduced CYP1A2 activity contributes to BC risk in different ways that include: i) a reduced activation of procarcinogens (i.e., HAs and PAHs) which may be protective from BC development; whereas ii) a reduced beneficial 
formation of 2-OHE1, which mutually allows the formation of the carcinogenic 16-OHE1, and iii) a decreased EETs production, which generates an inflammatory microenvironment, may be suitable conditions for the development and progression of $\mathrm{BC}$.

\section{Acknowledgements}

This study was funded/supported by the Università di Padova, Ricerca di Ateneo, Anno: 2007 - prot. CPDA072111, Italian Association for Research against Cancer (AIRC IG-6016).

\section{References}

1. Boussen H, Bouzaiene H, Ben Hassouna J, et al: Inflammatory breast cancer in Tunisia: epidemiological and clinical trends. Cancer 116: 2730-2735, 2010.

2. Maalej M, Hentati D, Messai T, et al: Breast cancer in Tunisia in 2004: a comparative clinical and epidemiological study. Bull Cancer 95: E5-E9, 2008.

3. Missaoui N, Jaidene L, Abdelkrim SB, et al: Breast cancer in Tunisia: clinical and pathological findings. Asian Pac J Cancer Prev 12: 169-172, 2011

4. Lichtenstein P, Holm NV and Verkasalo PK: Environmental and heritable factors in the causation of cancer. N Engl J Med 343 78-85, 2000.

5. Nebert DW, Dalton TP: The role of cytochrome P450 enzymes in endogenous signalling pathways and environmental carcinogenesis. Nat Rev Cancer 6: 947-960, 2006.

6. Nebert DW Yamazaki H, Shaw PM, Guengerich FP and Shimada T: Roles of cytochromes P450 1A2 and 3A4 in the oxidation of estradiol and estrone in human liver microsomes. Chem Res Toxicol 11: 659-665, 1998.

7. Tsuchiya Y, Nakajima M and Yokoi T: Cytochrome P450mediated metabolism of estrogens and its regulation in human. Cancer Lett 227: 115-124, 2005.

8. Zhou SF, Wang B, Yang LP and Liu JP: Structure, function, regulation and polymorphism and the clinical significance of human cytochrome P450 1A2. Drug Metab Rev 42: 268-354, 2010.

9. Wen ZH, Su YC, Lai PL, et al: Critical role of arachidonic acid-activated mTOR signaling in breast carcinogenesis and angiogenesis. Oncogene: Feb 20, 2012 (Epub ahead of print). doi: 10.1038/onc.2012.47.

10. Djordjevic N, Ghotbi R, Bertilsson L, Jankovic S and Aklillu E: Induction of CYP1A2 by heavy coffee consumption in Serbs and Swedes. Eur J Clin Pharmacol 64: 381-385, 2007.

11. Granfors MT, Backman JT, Laitila J and Neuvonen PJ: Oral contraceptives containing ethinyl estradiol and gestodene markedly increase plasma concentrations and effects of tizanidine by inhibiting cytochrome P450 1A2. Clin Pharmacol Ther 78: 400-411, 2005.

12. Kall MA, Vang O and Clausen J: Effects of dietary broccoli on human in vivo drug metabolising enzymes: evaluation of caffeine, estrone and chlozoxazone metabolism. Carcinogenesis 17: 793-799, 1996.

13. Lampe JW, King IB, Li S, et al: Brassica vegetables increase and apiaceous vegetables decrease cytochrome P450 1A2 activity in humans: changes in caffeine metabolite ratios in response to controlled vegetable diets. Carcinogenesis 21: 1157-1162, 2000.

14. Schrenk D, Brockmeier D, Mörike K, Bock KW and Eichelbaum MA: Distribution study of CYP1A2 phenotypes among smokers and non-smokers in a cohort of healthy Caucasian volunteers. Eur J Clin Pharmacol 53: 361-367, 1998.

15. Sinha R, Rothman N, Brown ED, et al: Pan-fried meat containing high levels of heterocyclic aromatic amines but low levels of polycyclic aromatic hydrocarbons induces cytochrome P4501A2 activity in humans. Cancer Res 54: 6154-6159, 1994.

16. Dobrinas M, Cornuz J, Oneda B, Kohler Serra M, Puhl M and Eap CB: Impact of smoking, smoking cessation, and genetic polymorphisms on CYP1A2 activity and inducibility. Clin Pharmacol Ther 90: 117-125, 2011.

17. Gunes A, Ozbey G, Vural EH, et al: Influence of genetic polymorphisms, smoking, gender and age on CYP1A2 activity in a Turkish population. Pharmacogenomics 10: 769-778, 2009.
18. Ghotbi R, Christensen M, Roh HK, Ingelman-Sundberg M, Aklillu E and Bertilsson L: Comparisons of CYP1A2 genetic polymorphisms, enzyme activity and the genotype-phenotype relationship in Swedes and Koreans. Eur J Clin Pharmacol 63: 537-546, 2007.

19. Nakajima M, Yokoi T, Mizutani M, Kinoshita M, Funayama M and Kamataki T: Genetic polymorphism in the 5'-flanking region of human CYP1A2 gene: effect on the CYP1A2 inducibility in humans. J Biochem 125: 803-808, 1999.

20. Pavanello S, Pulliero A, Lupi S, Gregorio P and Clonfero E: Influence of the genetic polymorphism in the 5'-noncoding region of the CYP1A2 gene on CYP1A2 phenotype and urinary mutagenicity in smokers. Mutat Res 587: 59-66, 2005.

21. Sachse C, Brockmöller J, Bauer S and Roots I: Functional significance of a C-->A polymorphism in intron 1 of the cytochrome P450 CYP1A2 gene tested with caffeine. Br J Clin Pharmacol 47: 445-449, 1999.

22. Pavanello S, B'chir F, Pulliero A, et al: Interaction between CYP1A2-T2467delT polymorphism and smoking in adenocarcinoma and squamous cell carcinoma of the lung. Lung Cancer 57: 266-272, 2007.

23. Pavanello S, Mastrangelo G, Placidi D, et al: CYP1A2 polymorphisms, occupational and environmental exposures and risk of bladder cancer. Eur J Epidemiol 25: 491-500, 2010.

24. Bonner MR, Bennet WP, Xiong W, et al: Radon, secondhand smoke, glutathione-S-transferase M1 and lung cancer among women. Int J Cancer 119: 1462-1467, 2006.

25. Qiu LX, Yao L, Mao C, et al: Lack of association of CYP1A2-164 A/C polymorphism with breast cancer susceptibility: a metaanalysis involving 17,600 subjects. Breast Cancer Res Treat 122: 521-525, 2010.

26. Mechanic LE, Marrogi AJ, Welsh JA, et al: Polymorphisms in XPD and TP53 and mutation in human lung cancer. Carcinogenesis 26: 597-604, 2005.

27. Pavanello S, Fedeli U, Mastrangelo G, et al: Role of CYP1A2 polymorphisms on lung cancer risk in a prospective study. Cancer genetics 205: 278-284, 2012.

28. Le Marchand L, Donlon T, Kolonel LN, Henderson BE and Wilkens LR: Estrogen metabolism-related genes and breast cancer risk: the multiethnic cohort study. Cancer Epidemiol Biomark Prev 14: 1998-2003, 2005.

29. Long JR, Egan KM, Dunning L, et al: Population-based casecontrol study of AhR (aryl hydrocarbon receptor) and CYP1A2 polymorphisms and breast cancer risk. Pharmacogenet Genomics 16: 237-243, 2006.

30. Kotsopoulos J, Ghadirian P, El-Sohemy A, et al: The CYP1A2 genotype modifies the association between coffee consumption and breast cancer risk among BRCA1 mutation carriers. Cancer Epidemiol Biomark Prev 16: 912-916, 2007.

31. Takata Y, Maskarinec G and Le Marchand L: Breast density and polymorphisms in genes coding for CYP1A2 and COMT: the multiethnic cohort. BMC Cancer 7: 30, 2007.

32. Bågeman E, Ingvar C, Rose $\mathrm{C}$ and Jernström H: Coffee consumption and CYP1A $2 * 1 \mathrm{~F}$ genotype modify age at breast cancer diagnosis and estrogen receptor status. Cancer Epidemiol Biomark Prev 17: 895-901, 2008.

33. Sangrajrang S, Sato Y, Sakamoto H, et al: Genetic polymorphisms of estrogen metabolizing enzyme and breast cancer risk in Thai women. Int J Cancer 125: 837-843, 2009.

34. Shimada N, Iwasaki M, Kasuga Y, et al: Genetic polymorphisms in estrogen metabolism and breast cancer risk in case-control studies in Japanese, Japanese Brazilians and non-Japanese Brazilians. J Hum Genet 54: 209-215, 2009.

35. Chang-Claude J, Beckmann L, Corson C, et al: MARIEGENICA consortium on genetic susceptibility for menopausal hormone therapy related breast cancer Risk. Genetic polymorphisms in phase I and phase II enzymes and breast cancer risk associated with menopausal hormone therapy in postmenopausal women. Breast Cancer Res Treat 119: 463-474, 2010.

36. Gulyaeva LF, Mikhailova ON, PustyInyak VO, et al: Comparative analysis of SNP in estrogen-metabolizing enzymes for ovarian, endometrial, and BCs in Novosibirsk, Russia. Adv Exp Med Biol 617: 359-366, 2008.

37. Quattrochi LC, Vu T and Tukey RH: The human CYP1A2 gene and induction by 3-methylcholanthrene. A region of DNA that supports AH-receptor binding and promoter-specific induction. J Biol Chem 269: 6949-6954, 1994.

38. Sogawa K and Fujii-Kuriyama Y: Ah receptor, a novel ligandactivated transcription factor. J Biochem 122: 1075-1079, 1997. 
39. Hankinson O: The aryl hydrocarbon receptor complex. Annual Rev Pharmacol Toxicol 35: 307-340, 1995.

40. Pavanello S, Pulliero A, Saia BO and Clonfero E: Determinants of anti-benzo(a)pyrene diol epoxide-DNA adduct formation in lymphomonocytes of the general population. Mutat Res 611: 54-63, 2006.

41. Martucci CP and Fishman J: P450 enzymes of estrogen metabolism. Pharmacol Ther 57: 237-257, 1993.

42. Meilahn EN, De Stavola B, Allen DS, et al: Do urinary oestrogen metabolites predict breast cancer? Guernsey III cohort follow-up. Br J Cancer 78: 1250-1255, 1998.

43. Muti P, Bradlow HL, Micheli A, et al: Estrogen metabolism and risk of breast cancer: a prospective study of the $2: 16 \alpha$ hydroxyestrone ratio in premenopausal and postmenopausal women. Epidemiology 11: 635-640, 2000.
44. Kabat GC, Chang CJ, Sparano JA, et al: Urinary estrogen metabolites and breast cancer: a case-control study. Cancer Epidemiol Biomarkers Prev 6: 505-509, 1997.

45. Liehr JG and Ricci MJ: 4-Hydroxylation of estrogens as marker of human mammary tumors. Proc Natl Acad Sci USA 93: 3294-3296, 1996.

46. Telang NT, Suto A, Wong GY, Osborne MP and Bradlow HL: Induction by estrogen metabolite 16-hydroxyestrone of genotoxic damage and aberrant proliferation in mouse mammary epithelial cells. J Natl Cancer Inst 84: 634-638, 1992. 